\title{
Institutional analysis of environmental management practices of golf courses in Andalusia
}

\author{
Francisco J. Riquel-Ligero ${ }^{1}$
}

Received: 27/07/2011

${ }^{1}$ University of Huelva (Spain), GEIDETUR, phone: + 34 626380054, e-mail: francisco.riquel@dem.uhu.es

Supervisor: Dr. Alfonso Vargas-Sánchez

Institution awarding the Ph. D. Degree: University of Huelva

Date of defence: $12^{\text {th }}$ November 2010

(c) 2011 International University College. All rights reserved

Citation: Riquel-Ligero, F. J. (2011), Institutional analysis of environmental management practices of golf courses in Andalusia. Doctoral dissertation summary. European Journal of Tourism Research 4(2), pp. 229-232

\section{Goal and objectives of the dissertation Goals:}

1. Review of seminal papers about the Institutional Theory.

2. Review of papers published in top journals about the Institutional Theory, especially on its application in the tourism industry.

3. To describe the institutional environment with a direct influence on the performance of golf courses in Andalusia.

4. To analyze the change of paradigm in business, from the classic economic view to a new environmental view, showing their main implications to organizations.

5. To provide a valid econometrical methodology for the study of the institutional pressure.

\section{Objectives:}

In this thesis we study the institutional framework with a direct influence on the environmental performance of golf courses, analyzing the various mechanisms we have found that foster an isomorphism in practices respectful with the environment. In this line, we have set as a main objective to characterize the context in which Andalusia golf courses conduct their business, under the approach favoured by the Institutional Theory, and relating this theoretical framework with the adoption by Andalusia golf courses of environmentally sustainable practices.

\section{Methodology}

In the first part of this thesis we have used a methodology based on a review of the literature that helped to create the Institutional Theory, as well as its more recent developments and applications in organization studies. A second part is guided to describe and analyze the Andalusia golf courses industry and its impacts, such as its repercussions in the regional economy and in the Andalusian tourism. In this part we have created a list of the main international environmental initiatives and their implications in the sustainable tourism concept. The last part is devoted to the empirical study, in which we have used the Partial Least Square technique for testing the hypothesis of our research model. The instrument used to obtain 
the data is a structured questionnaire addressed to the greenkeepers and/or managers of the Andalusian golf courses, since they are the individuals who should have the most direct information needed to respond to the questions asked. A preliminary version of the questionnaire was tested by several university researchers, with experience in this type of studies, and by several managers of golf courses. The object of this test was to ensure the validity of content of this instrument of measurement. Having, thus, validated the questionnaire, it was implemented in the population being studied, that is, the 96 golf courses in Andalusia that were in active operation during the year 2009 . We have taken a level of confidence of $95 \%$; the sampling error obtained with the final sample is $7.42 \%$; and $p=q=0.5$. A total of 34 completed questionnaires were received but 3 of these were not completed correctly and had to be discarded. Thus the total of valid responses was 31, representing a response rate of $32.29 \%$ of the population. The scales utilized to measure the constructs were of five-pointsLikert type. We finish with our conclusions, limitations and future research lines.

\section{Results}

Concerning the institutional context that we have identified and defined, we can conclude, following the values of composite reliabilities obtained, that all the constructs considered in this study have a fairly acceptable degree of internal consistency. Similarly, we can state that at least $50 \%$ of the variance of all the constructs is due to their indicators; therefore convergent validity is another of the characteristics to be noted, particularly in respect of the constructs that form the institutional context.

It can also be stated that the mechanism that has the most incidence in the application of environmental management practices in these organizations is the coercive pressure. Second in influence is the mimetic pressure; and third is the normative pressure, which is found to be less well-developed. This proposition is motivated by the great diversity of standards that exist in relation to the activities of golf course management, and their relationship to the natural environment, and especially by the approval of a new legislation (Decree 43/2008) that regulates the establishment and functioning of golf courses in Andalusia, with many environmental implications.

Another of the conclusions that merits emphasis refers to the importance of the concept of legitimacy, understood broadly as social acceptance. It has been demonstrated in the study that the principal motivation for operating practices that are environment friendly is to obtain social legitimacy - more important, even, than to improve the financial results. Moreover, the managers interviewed do not believe that a greater legitimacy necessarily generates better returns for them. They are similarly sceptical that putting environmental policies into practice represents a better organizational performance for them. The preceding statement lends weight to the conclusion that being respectful of the natural environment is important for these golf courses because it brings them the social acceptance and, indirectly, the customers and resources needed to ensure their survival.

\section{Theoretical conclusions}

We can state that the pressure of coercive character are those that exert the greatest influence on the application of sustainable environmental practices by the golf courses of Andalusia. This conclusion differs from those reached in other studies of so-called green institutionalism, such as that of Jennings and Zandebergen (1995) in which it is stated that normative pressure has a greater impact on the spread of concepts and practices related to sustainability. However, there are many other studies that reach the same conclusion as ours on the strength of coercive pressure on the application of good environmental practices; among them are those by King and Lenox (2000), Palmer and Richard (2001), Timothy and Rodney (2005) and Vargas and Riquel (2010). In the case of the business sector in which the golf courses of Andalusia operate, coercive pressure are predominant in the configuration of the institutional context. This is due principally to the existence of numerous regulatory authorities that promote these practices. Another important factor is the 
interest of the managers of this type of organisations in achieving social legitimacy through strict compliance with the relevant laws, regional regulations and local ordinances. These findings are in line with those reported in the studies of Kostova and Roth (2002) and Llanas (2005).

Equally important, we reaffirm the postulates of the classic authors of institutionalism, like DiMaggio (1991), Deephouse (1996), Bansal and Kendall (2000), Mintzber and Westley (2000) and Bansall and Clelland (2004), that the desire to obtain legitimacy in the institutional context is the main factor explaining the behaviour and responses of organisations in respect of environmental sustainability.

\section{Practical application of the dissertation}

Our aim with this thesis is to contribute to the studies termed "environmental or green institutionalism", but from a perspective of organizations related to tourism, and we believe this thesis provides additional knowledge to this field of research. We can state that the present thesis responds to the appeal made by authors such as DiMaggio and Powell (1983), Scott (1995) and Tolbert and Zucker (1996) regarding the need for empirical studies that would help to consolidate the Institutional Theory. In this context, Tolbert and Zucker (1996) claim that there is little consensus on the research techniques and methodologies, that are most appropriate for the institutionalist approach. With this study we have provided a statistical methodology for the theoretical framework of institutionalism that is valid for testing its principles. To date there are virtually no previous studies that have used the PLS methodology for this purpose, particularly in organizations that are not linked to the public sector and are subject to market pressure and competition.

In our view, the PLS technique has validity and contributes to explaining the management styles, the practices, strategies and analysis of the institutional context. This has been the principal concern of the institutionalist studies undertaken in the last decade (Fernández, 2001).
We believe that this thesis demonstrates that the institutional pressure of the business and market context should be taken into account in order to understand the environmental behaviour of all types of organization, and of golf courses in particular; it also demonstrates the growing interest in the application of practices for the sustainable management of the natural environment that confers social legitimacy on such organizations.

\section{Content of the dissertation}

\section{Abstract of chapter one}

In this chapter we make a checklist of the main papers about Institutional Theory. Firstly, we differ between old and new institutionalism; and the principal concepts of this Theory are reviewed. We finish presenting the more important research lines, with particular attention to the development of the called "green institutionalism".

\section{Abstract of chapter two}

The second chapter is dedicated to analyze the environmental management of the companies under study; we start describing the origin and the content of the paradigm of Corporate Social Responsibility, which serves as an umbrella. Afterwards, the more usual norms about environmental responsibility are detailed.

\section{Abstract of chapter three}

Our analysis unit, the golf course, is described: its origin, classifications and the relationship between tourism and golf. Specifically we develop the most commonly accepted standards in the sector, such as Audubon Cooperative Sanctuary program, the biosphere golf system, and The Committed to Green by the European Golf Association. In this chapter we also explain the specific Decree 43/2008 dictated by the regional government, which stipulates the conditions of location, configuration and functioning of golf courses in Andalusia.

\section{Abstract of chapter four}

With this chapter starts the empirical part: the research model and its hypothesis are justified, as well as we describe the research methodology, technical specifications of the sampling and questionnaire design. 
Institutional analysis of environmental management practices of golf courses in Andalusia. Doctoral dissertation summary.

\section{Abstract of chapter five}

This is the second chapter of the empirical part, devoted to the statistical analysis in which the Partial Leas Square (PLS) technique is implemented using the software Visual-PLS. Nevertheless, before to the PLS analysis, we dedicate a section of the chapter to depict this econometrical technique to be able to estimate the measurements models and the structural model. The model estimated has helped us make a testing of the hypothesis in the model.

Abstract of chapter six

The last chapter is reserved to theoretic and empirical conclusions, limitations and future research lines. Also we include a summary our objectives and some management implications. 